\title{
Novel approach to treat fecal incontinence with muscle stem cell-based therapy
}

\author{
M. Siemionow ${ }^{1}$
}

Received: 23 September 2015/Accepted: 23 September 2015/Published online: 17 October 2015

(C) Springer-Verlag Italia Srl 2015

It is a pleasure to provide the commentary on the pioneering work of Dr. Romaniszyn and colleagues entitled: "Implantation of autologous muscle-derived stem cells in treatment of fecal incontinence: Results of an experimental pilot study" [1].

Introduction of stem cell-based therapies in the past decade has opened a new treatment options for many disease and clinical conditions where standard therapies have either failed or were ineffective [2]. Fecal incontinence (FI) represents a challenging clinical and healthcare problem. Current methods of treatment both conservative, including pharmacotherapy, biofeedback, silicone elastomer prosthesis (Acticon Neosphincter ${ }^{\mathrm{TM}}$ ) [3], as well as radio-frequency energy delivery, and surgical such as sphinctotherapy are not optimal, and long-term results are not satisfactory [4].

This creates a significant medical and social problem in large population of patients with fecal incontinence and affects their daily leaving activities and quality of life. In addition, the financial burden to treat FI as well as related complications is substantial and exceeds $\$ 4000$ per year in both Europe and the USA [5].

Thus, there is an urgent need to search for new methods and approaches to treat fecal incontinence. Several innovative approaches have been proposed and tested including new devices, pharmacological agents, new biofeedback programs, and sacral and posterior tibial nerve stimulation. However, none of these approaches became a standard of

M. Siemionow

siemiom@hotmail.com

1 Department of Orthopaedics MC 944, University of Illinois at Chicago, 900 South Ashland Avenue, 3356 MCBRB, Chicago, IL 60607, USA care; thus, the stem cell-based therapies seem to have the best therapeutic potential.

Several investigators have published promising results using stem cell therapies in experimental models of incontinent rodents and mongrel dogs $[6,7]$. On the basis of existing data, local myoblast [8] and intravenous MSC therapies [9] have achieved the best results.

There are numerous reports on clinical application of myoblasts and MSC in treatment of urinary incontinence and muscular dystrophies [10, 11]. Limited data are available with regard to cell therapies in FI patients even though already published results are encouraging [12].

The clinical study of Romaniszyn et al. is representing an innovative approach to treat FI with autologous myoblasts. This pilot prospective experimental clinical trial was approved by appropriate ethical committees and is summarizing the outcomes of ten patients with FI enrolled into the study and treated with autologous muscle-derived stem cells. The standard methods of assessment were employed, including Incontinence Severity Index (ISI) questionnaire, anorectal manometry, surface endoanal electromyography, endorectal ultrasound, and clinical examination. Nine patients were followed up to 12 months. Overall, functional tests confirmed that myoblast stem cell therapy improved continence in 4 patients $(44.4 \%)$.

This pilot study on a small group of patients has several limitations that were raised by the authors in the Discussion section of the article. These include sparse cohort, dispersal of the patients' age, short follow-up, postoperative evaluation by means of subjective questionnaire, and postimplantational edema that may be responsible for a "placebo effect." Furthermore, this method can be applied only in patients with undamaged sphincter innervation. The description of method of myoblast transplantation including clear outline of sites of implantation procedure as well 
as the number of cells used per injection is helpful for investigators interested in using this approach for treatment of fecal incontinence. This will allow to compare results generated by different centers and will support application of this therapy as a standard of care in the near future.

The most important points which have to be emphasized include results which confirm that the therapy was safe and no complications were reported after cell injection. Romaniszyn and his team applied well-investigated model that proved to be effective in using myoblasts for treatment of different muscle disorders, since the first trials in the late 1970s [13]. In addition, it has to be emphasized that application of autologous cells does not generate immune response and thus is safer compared with allogenic cells application which requires immunosuppression and exposes patients to its harmful side effects. Besides subjective questionnaire, investigators applied more objective methods to assess sphincter performance, including anorectal manometry, surface endorectal EMG, and ERUS. Myoblast activity was confirmed, using surface electromyography rectal probe.

Since the results of the study are encouraging, it will be important that this pilot trial serves as the basis for a clinical trial with a larger cohort of patients and with defined inclusion and exclusion criteria. In addition, therapy kinetics, including stem cell number and timing of cell delivery, has to be still established.

In summary, the authors have to be congratulated on the conducted clinical study using myoblast stem cell therapy as an innovative approach to treat fecal incontinence. Once the stem cell protocol is defined and its therapeutic effect confirmed in a large population of patients with fecal incontinence, this method may become a standard of care helping many patients who are currently suffering from this socially withdrawing clinical condition.

\section{Compliance with ethical standards}

Conflict of interest The authors declare that they have no conflict of interest.

Ethical approval This article is an editorial and does not contain any studies with human participants or animals performed by the author.
Informed consent For this type of study (editorial) formal consent is not required.

\section{References}

1. Romaniszyn M, Rozwadowska N, Malcher A, Kolanowski T, Walega P, Kurpisz M (2015) Implantation of autologous musclederived stem cells in treatment of fecal incontinence: results of an experimental pilot study. Tech Coloproctol. doi:10.1007/s10151015-1351-0

2. Trounson A, Courtney McDonald C (2015) Stem cell therapies in clinical trials: progress and challenges. Cell Stem Cell 17:11-22

3. Wong MT, Meurette G, Wyart V, Glemain P, Lehur PA (2011) The artificial bowel sphincter: a single institution experience over a decade. Ann Surg 254:951-956

4. Madoff RD, Rosen HR, Baeten CG (1999) Safety and efficacy of dynamic muscle plasty for anal incontinence: lessons from a prospective, multicenter trial. Gastroenterology 116:549-556

5. Bharucha AE, Dunivan G, Goode PS et al (2015) Epidemiology, pathophysiology, and classification of fecal incontinence: state of the science summary for the National Institute of Diabetes and Digestive and Kidney Diseases (NIDDK) workshop. Am J Gastroenterol 110:127-136

6. Bisson A, Fréret M, Drouot L et al (2015) Restoration of anal sphincter function after myoblast cell therapy in incontinent rats. Cell Transplant 24:277-286

7. Oh HK, Lee HS, Lee JH et al (2015) Functional and histological evidence for the targeted therapy using biocompatible polycaprolactone beads and autologous myoblasts in a dog model of fecal incontinence. Dis Colon Rectum 58:517-525

8. Saihara R, Komuro H, Urita Y, Hagiwara K, Kaneko M (2009) Myoblast transplantation to defecation muscles in a rat model: a possible treatment strategy for fecal incontinence after the repair of imperforate anus. Pediatr Surg Int 25:981-986

9. Salcedo L, Penn M, Damaser M, Balog B, Zutshi M (2014) Functional outcome after anal sphincter injury and treatment with mesenchymal stem cells. Stem Cells Transl Med 3:760-767

10. Shokeir AA, Harraz AM, El-Din AB (2010) Tissue engineering and stem cells: basic principles and applications in urology. Int J Urol 17:964-973

11. Skuk D, Goulet M, Roy B et al (2007) First test of a "highdensity injection" protocol for myogenic cell transplantation throughout large volumes of muscles in a Duchenne muscular dystrophy patient: eighteen month follow-up. Neuromuscul Disord 17:38-46

12. Frudinger A, Kölle D, Schwaiger W, Pfeifer J, Paede J, Halligan S (2010) Muscle-derived cell injection to treat anal incontinence due to obstetric trauma: pilot study with 1 year follow-up. Gut 59:55-61

13. Lipton BH, Schultz E (1979) Developmental fate of skeletal muscle satellite cells. Science 205:1292-1294 